PJOS 5(2), 2013

\title{
Peircean Index in the Naming Process: Nouns, Pronouns and Proper Names
}

\author{
Donna E. West ${ }^{1}$ \\ Department of Modern Languages, State University of New York at Cortland, USA
}

\begin{abstract}
This analysis identifies semiotic differences between pronouns, proper names and count and mass nouns. It showcases the work of Peirce's Index in the process of individuation, capitalizing upon the ontological and epistemological effects of employing pronouns (particularly demonstratives) as individuals, as opposed to their use as singulars. Peirce's individual versus singular distinction highlights the contrast between unique separateness, on the one hand, and similarity among entities (i.e., object classification) on the other. The argument is likewise made that while pronouns are often used as individuals, nouns and most proper names have a singular function. Rationale supports the fact that this difference results from the prominence of Peirce's Dynamical Object in the work of embodied schemas which underlie and permeate new experiences. Dynamical Objects of demonstrative pronouns ground the triad, while Interpretants ground triads for nouns and proper names.
\end{abstract}

\section{Introduction}

This inquiry will establish how pronouns and proper names serve as individuals versus singulars (a primary Peircean distinction), as measured by the relative power of Objects to select their signs, particularly indexical ones - their potency to ground the triad. It further addresses how nouns qualify as singulars only, and how the Object plays a less foundational role in establishing their triadic relations.

Three lexical categories illustrate distinct semiotic matrices within Peirce's triadic relations: pronouns, proper names and common nouns (count, mass). Whereas Peirce clearly considers pronouns and some uses of proper names to be quintessential illustrations of Index as set forth in (1897) CP 3.460 ("An indexical word, such as a proper noun, or demonstrative, or selective pronoun, has force to draw the attention of the listener to some haecceity common to the existence of speaker and listener.") he considers nouns and most cases of proper names to be symbols.

\begin{abstract}
A symbol is a representamen whose special significance or fitness to represent just what it does represent lies in nothing but the very fact of there being a habit, disposition, or other effective general rule that it will be so interpreted. Take, for example, the word "man." These three letters are not in the least like a man; nor is the sound with which they are associated. Neither is the word existentially connected with any man as an index. It cannot be so, since the word is not an existence at all. The word does not consist of three films of ink. If the word "man" occurs hundreds of times in a book of which myriads of copies are printed, all those millions of triplets of patches of ink are embodiments of one and the same word. I call each of those embodiments a replica of the symbol. This shows that the word is not a thing. What is its nature? It consists in the really working general rule that three such patches seen by a person who knows English will effect his conduct and thoughts according to a rule (c. 1903: CP 4.447)
\end{abstract}

${ }^{1}$ Email: westsimon@twcny.rr.com 
With respect to each, a qualitatively different relationship holds between the Sign, Object and Interpretant. With Index, Peirce considers Sign/Object relations to be paramount: "an Index ...would at once lose the character which makes it a sign if its Object were removed, but would not lose such character if there were no Interpretant," (1901: CP2.304). With Symbols, emphasis is fundamentally on the relationship between Sign and Interpretant: "A symbol is a sign which would lose the character which renders it a sign if there were no interpretant. Such is any utterance of speech which signifies what it does only by virtue of its being understood to have that signification" (1901: CP 2.304). In other words, it is the meaning or significate effect of the Sign (its Interpretant) which dominates within a symbolic triad, whereas within the Indexical triad it is the Object which dominates.

Accordingly, Indexes have a procedural function in events, directing attention to an entity and to spatial and temporal fields contiguous to that entity in the here and now of use (typically co-occurring with the Object and hence emphasizing individual status. Symbols, on the other hand, have a more substantive or declarative function characterizing events in terms of their relative qualities and hence representing relations of resemblance/analogy between sign and Object. As such, the nature of symbols (together with their meanings) is to supply the conceptual framework of the argument or proposition; and in doing so, they implicitly express their Object's membership in one or more classes. Conversely, the business of Index is to impose a spatial and temporal matrix on objects - those in the here and now and in memory in absent or imagined places. Essentially, whereas Indexes situate objects according to an orientation, symbols comparatively profile objects within an ontological hierarchy.

Five functions of Index exist for Peirce according to Atkin (2005: 163-164) and none of these attributes require a causal relationship between Index and Object (Atkin, 2005: 179-181). Three of these are of primary importance to illuminate the representational distinction between pronouns and proper names/nouns: physical contiguity between Sign and Object, absence of analogy as embodied in resemblance or law-like relations, and reference to individuals (1901: 2.306, 1903: 4.447). "Thus, while demonstrative and personal pronouns are, as ordinarily used, 'genuine indices,' relative pronouns are 'degenerate indices'..." (1901: CP 2.305). Although all three attributes of Index exemplify pronoun use, the latter (reference to individuals) chiefly characterizes the fundamental distinction between pronouns and the two other lexical categories, since individuals or "designatives" as Indexes are clearly differentiated from singulars (nouns and proper names), which do not necessarily qualify as Indexes.

This analysis will first demonstrate that pronouns (especially demonstratives) qualify as Indexes consequent to their character as individuals; as such, they rely heavily upon their Objects and other Indexes for referential meaning. Thereafter, rationale will be offered as to how nouns and most uses of proper names are quintessential symbols, and qualify as singulars; and how they depend upon their Interpretants (not their Objects) to supply meaning. Finally, Peirce's distinction between the Dynamical Object and the Immediate Object will be discussed in light of the individual nature of pronouns and the singular nature of nouns and proper names. The discussion will showcase the attentional character of demonstrative pronouns in the physical context versus reliance on featurebased comparisons accessed from memory, inherent in nouns and proper name use. 
PJOS 5(2), 2013

\section{Types of individuation}

Peirce's concept of individuation sheds particular light upon the three-way distinction between pronouns, proper names, and count nouns as names. In MS 931: 24 (1868) and MS 280: 27 (c. 1905), lies the crux of Peirce's argument articulating the significant distinction between pronouns and proper names, on the one hand, and count and mass nouns on the other. Despite the wide interval of some thirty-seven years in the composition of the MSs (1868 for the former, c. 1905 for the latter), a surprising congruity of perspective holds. In MS 931: 24 (1868), Peirce distinguishes two types of individuation: singulars and individuals.

\footnotetext{
But here it is necessary to distinguish between individual in the sense of that which has no generality and which here appears as a mere ideal boundary of cognition, and an individual in the far wider sense of that which can be only in one place at one time. It will be convenient to call the former a singular and the latter an individual...while singulars are real they are so only in their generality; singulars in their absolute discrimination or singularity are mere ideas.... In short, those things which we call singulars exist, but the character of singularity which we attribute to them is selfcontradictory. With reference to individuals, I shall only remark, that they are certain general terms whose objects can only be in one place at one time, and these are called individuals. They are generals, not singulars.
}

Peirce's concept of singular refers to "boundaries of cognition ... mere ideas." He follows with the observation that singulars are "self-contradictory." Singulars are selfcontradictory in the sense that they are not strictly single referents; rather they refer to classes of objects by virtue of their status as count and mass nouns. ${ }^{2}$ Their "singularity" is singular only in the sense that the term is the sign for a group of Objects, a type. In (1) the noun $d o g$ expresses a type, in that it implicitly compares the referent canine's conduct to that of others of the same species.

(1) The dog evinces ferocious tendencies.

The noun $d o g$ represents a category, even though it individuates a particular dog. Hence, even count nouns which refer to particulars do not function primarily to designate single entities apart from comparisons with entities of the same class/kind. Peirce's reference to "boundaries of cognition" finds its mark in count and mass noun use, in that, in a similar sense, these names demonstrate where concepts begin and end, i.e., each instantiation of the category DOG provides information regarding the speaker's semantic and world knowledge of the concept/kind - whether DOG constitutes a central exemplar or a more peripheral one (cf. Rosch et al., 1976). In short, $d o g$ when used as a count or mass noun delimits "boundaries of cognition" in each of its uses, in that it refers to typical or less typical instantiations of the concept DOG. "Boundaries of cognition" operate when concepts (DOGNESS) guide how names fit to Objects which share primary attributes. The word $d o g$ is a name which expresses that its Object at the time of reference qualifies as a

\footnotetext{
${ }^{2}$ According to Salthe (1993: 141), classes are primarily a consequence of linguistic artifacts; and even tokens can be subject to class inferences: "Classes and types differ primarily in that tokens of types are explicitly acknowledged to have (immediately irrelevant but pregnant) differences among themselves. In addition classes are usually taken to be artifacts of human discourse - products of linguistic discourse."
} 
member of the class of canine. The influence of "boundaries of cognition" is foundational then, to define singulars (count and mass nouns).

In contrast, individuals, such as pronouns (quintessentially demonstratives) and perhaps proper names in their initial uses, function to refer to "...certain general terms whose objects can only be in one place at one time." Pronouns qualify as individuals in that they are "generals." They are such when they designate any object - focus can shift from one entity to another ad infinitum in the context, without specifying any features (perceptual or functional) which all of their referents share. In point of fact, referents of demonstratives are hard pressed to have any attributes in common with other uses of that or it, (West, 2011: 95, 2013), although for personal pronouns, certain features such as gender, ordinarily need to be specified. More specifically, a that on one occasion of use might refer to the trunk of an elephant, while on another occasion of use (even within the same discourse) that might well refer to a vehicle present in the context, to an absent something, or even to a more abstract entity such as a constructed idea. Because deployment of these pronouns is not instigated by notice of similarities among referents (as is the case for count and mass nouns, e.g., quadripedal, hairy, tailed animals, for $d o g$ ) their Interpretants (meaning and consequences of the Sign-Object connection) do not depend upon class-based comparisons. ${ }^{3}$ Instead, pronouns, as individuals, refer to any entity which happens to become instantiated in the speaker's line of focus. ${ }^{4}$ Pronouns (especially demonstratives) likewise qualify as individuals because they "can only be in one place at one time." This existential restriction to the here and now ensures them their individual identity, in that each is "picked out" for its individuality, rather than being packaged as an exemplar of a class of things. In (2), the referent of that is considered apart from other referents, as unique from all others in terms of its degree of affirmative affect.

(2) We adore that.

The referent here has been afforded superlative status, as being the most noticed or the most desirable. So, if any comparison is operating in the process of singling out individuals, it is expressed in terms of an absolute for the category under consideration. Furthermore, the rather empty semantic content of these pronouns (not specifying any perceptual or functional characteristics) makes possible their use (particularly that which is existential in nature) as individuals. Nonetheless, these pronouns can likewise be employed as singulars, if their semantic meaning contains distance related and orientational information categorizing Objects with respect to a point of reference. Both proximal and distal demonstratives (e.g. this and that) in their contrastive use unequivocally constitute singulars. When these contrastive uses of the demonstrative pronoun predominate, their individuating function is singular, as opposed to the more common individual use of that attending to a single Object in the immediate context of

\footnotetext{
${ }^{3}$ Hilpinen (2012: 271) makes a useful distinction which parallels the individual versus singular contrast, in distinguishing between embodied and disembodied names. The former aligns itself with Peirce's individual kind, while the latter is equivocal to Peirce's singulars.

${ }^{4}$ Other less typical uses of demonstrative pronouns do entail some classification, when they are employed contrastively and establish a point of reference, namely speaker. Ordinarily both this and that are associated with an Interpretant, i.e., this representing an Object near to speaker and that referring to Objects far from speaker (West 2011: 95).
} 
PJOS 5(2), 2013

use. In short, more typical uses of demonstrative pronouns (particularly that as an attentional catch-all) encapsulate Peirce's individual function, because their use places emphasis not on having sufficient properties to qualify as an $\mathrm{X}$, but on the location and attentional worth of the referent.

This way of knowing Objects, by attentional means, constitutes a significant extension of Peirce's perspective in the New List of Categories in 1867 (EP1: 1-10). In the New List of Categories, Peirce restricts knowledge of Objects to information gleaned from their properties. In a word, it is only via their qualia that Objects can be known: "conception of being unites properties of substance," (EP1: 3-4). But, as a consequence of Kantian-based influences, Peirce further integrated the issue of continua into his model (DiLeo 1991: 86). The work of Duns Scotus ${ }^{5}$ likewise wrought expansions in Peirce's model beyond 1885, particularly resultant from Scotus' notions of haecceity and contraction. ${ }^{6}$ Accordingly, in 1885 , Peirce began referring to attentional devices such as Index as an agent for collecting knowledge about Objects. "That which all things have which makes them individuals... [it is] blind insistency. Nature crowds its way into a place in the world. This is the haecceity, it is much the same as Secondness," (n.d., n.p.: MS 1000: 2). Knowing Objects then, can be enhanced by focus on the Object in the "there" and "then" of the context, not from knowledge of their properties alone. With the elevation of attentional devices in Secondness to inform about Objects arises the increased importance of signs as individuals. The purpose of individuals, in the naming enterprise, is heightened since individuals emphasize the uniqueness of Objects, independent of their physical or functional features. This permits the space and time of the semiotic event to supply primary information about the being and substance of Objects.

Peirce sheds further light on both types of individuation (singulars, individuals) in MS 280: 27. "The individual...is that which is in every respect determinate. It is, therefore, the instantaneous state of an existent. The singular...is that which has a continuity of existence in time and at instant is absolutely determinate." Peirce's claim that an individual is "in every way determinate" implies the underlying function of the individual to be determined by its Object on each occasion of use, i.e., all Sign - Object relations of the individual type are determined by virtue of the discrete properties which

\footnotetext{
${ }^{5}$ Peirce's interest in issues of haecceity has its basis in Duns Scotus' model which gives primary place to realism and oneness in ontological pursuits. For further explanation of haecceity, cf. DiLeo (1991) and Duns Scotus' Early Oxford Lecture on Individuation, translated by Fr. Allan Wolter, particularly the Introduction. ${ }^{6}$ Peirce's earliest mention of haecceity materialized in 1886 (W5:389). Shortly thereafter, in 1889, he contributed the following entry to the Century Dictionary: "[This word was formed by Duns Scotus about 1390 (sic), and was based, as he explained, upon the fem. Pronoun because the abstract quality 'thisness' is fem. as being expressed, in L., like other abstract qualities, by a noun with the fem. suffix -ta (t-)s .... That element of existence which confers individuality upon a nature, according to the Scotists, so that it is in a particular place at a particular time; hereness and nowness. [...] Scotus maintained that a material substance is made individual, not by its own formal nature, by its quantity, or by its matter, but only by a distinct mode of being, like that which distinguishes a living reality from an idea. This is what he meant by a "positive determining entity," where entity must be distinguished from ens" (CD 2677). Peirce rejected Scotus' notion of contraction (a direct outgrowth of his concept of realism and hence haecceity) in favor of concretion (cf. DiLeo 1991: 98; Riley 1974: 142 for further discussion of the legitimacy of concretion.)
} 
account for their individuation without implicit reference to other of that Sign's pairings. No instantiation of that intimates features of any other that as if it needed to be admitted to a class of similar thats. In fact, any potential Object can be afforded "that" status (status as an existent which merits individuation) independent of any meaning accorded to the Sign's over-all use. Conversely, instantiations of singulars, although determinate, are so only in each instantiation (not with respect to over-all meaning/use). When singulars emphasize their Objects' membership in a class and hence imply shared attributes with other members of that class, their purpose is not to determine a particular object, but to emphasize how the object fits into a category of similar objects.

By "instantaneous state of an existent" Peirce refers to the sudden entrance of the referent into the mind of the observer, to impel his/her attention to notice it as an individual in the Peircean sense. Noticing the individual entails attention to the Object of focus in its uniqueness, without any intimation of similarity to any other Object. Objects in this capacity are referents to which interpreters react in the course or stream of existence. They are especially prominent when they constitute moderately novel entities for the event participants. In fact, the Object here impinges on the mind of the observer to such a degree that its presence eclipses all others, reifying Peirce's alignment with the issue of haecceity. Peirce's infusion of haecceity (whether explicitly or implicitly) into the fiber of the naming process underscores the fundamental difference between individuals and singulars. Whereas individuals are signs whose Objects are attentional agents in the here and now of context, showcasing their nearness (haecceity-based) and pragmatic dependence, singulars are largely interpreted via a more established, more objective standard. As such, singulars have "continuity" - they bring with them (from within their lexicon) properties/attributes which determine their category as referents over occasions of use. In this way, singulars as signs (unlike individuals) express commonalities among referents and give rise to similar meanings across uses. Their continuity resides in the fact that their Interpretants carry this meaning across uses packaging Objects of singulars into bundles of cognition. The continuity which Peirce identifies resides in application of the same sign and Interpretant to different Objects which are deemed to warrant inclusion in an identical category. As such, instantiations of singulars, despite their determinateness, are exemplars of a composite, the Immediate Object. Unlike pronouns, singulars bring a host of similarly situated Objects and experiences to mind (in the Immediate Object), not the instantiated Object (Dynamical Object) alone. Thus, their function referentially and semantically is quite distinguishable from that of pronouns on most occasions of use.

\section{Intricacies of proper name use}

Determining whether proper names are individuals or singulars is not as clean a process - they may be categorized as either. Proper names meet muster as individuals only when they serve as Indexes (indexical legisigns); otherwise, they qualify as singulars. Like pronouns, proper names fit Peirce's individual sense of individuating in their initial use.

A proper name, when one meets it for the first time, is existentially connected with some percept or other equivalent individual knowledge of the individual it names. It is then, and then only, a genuine 
PJOS 5(2), 2013

Index. The next time one meets with it, one regards it as an Icon of that Index. The habitual acquaintance with it having been acquired, it becomes a Symbol whose Interpretant represents it as an Icon of an Index of the individual named. (1902: CP 2.329-from the Syllabus).

When met for "the first time," when someone is introduced, for example, it is only the physical referent (and perhaps its immediate context) which determines the assignment of the name, prior to any knowledge or mental image of the referent. This "existential" requirement of first uses of proper names unequivocally qualifies them as individuals, illustrating their function as agents of attention in haecceity. Moreover, they qualify as individuals (instruments of near space and time) as a direct consequence of their status as Indexes, as Peirce articulates in the above entry. When they are met for the first time, their Object is a person devoid or nearly so of iconic memories of that person; and the association by spatial contiguity that holds between Object and proper name requires the sign's primary function to be indexical. This use of proper names is devoid of associations of the person's (constituting the Object) habits of conduct or character. According to Hilpinen (2012), these uses of proper names should not be called symbols. Rather, proper names behave similarly to the undifferentiated uses of that; and the Interpretant is an empty slot to be filled later with various and sundry Iconic and Symbolic associated information. Moreover, because no mental standard exists (semantic knowledge) to determine (by comparison) whether the person's conduct/appearance conforms to any standard; the proper name refers only to particulars in the context. It forces dependence on contextually based spatial components which haecceity affords. In short, like pronouns, proper names in their initial use are not associated with Interpretants whose meaning relies on concepts or "boundaries of cognition;" rather, their interpretation is scaffolded upon features of the near context, especially alive in the haecceity of the moment.

It is not until proper names are employed for the second time that they transcend their individual function. Their second use appears to take a significant step toward acquiring a singular function, since, in this use proper names are accorded iconic status: "The next time one meets with it [the proper name], one regards it as an Icon of that Index," (1905: MS 280: 27). Whereas the Index characterizes first uses of proper names, the Icon insinuates itself in second uses. The iconic status is a direct consequence of the near look-alike nature of the Interpretant (the memory of the first instantiation of the proper name's Object), especially given the flashbulb-like equivalence (in the form of visual similarity) which working memory affords between the physical Object (the initial referent of the proper name) and its mental representation, its Interpretant. In a word, the referent of the name and its Interpretant (iconic memory) concretely resemble one another; but the Sign ordinarily does not do so, absent the influence of its Interpretant, i.e., the mental image of the person bears resemblance to the person, whereas Peter only serves as a composite for all attributes of the person. Since similarity between the Object and the Interpretant is strong in second uses of the proper name, the Sign (given its association with a single person) need not exist in the same spatio-temporal context with the Object, and need not conform to features of haecceity. All that is necessary in second uses is that the sign-vehicle match the prefigured iconic memory of the Sign - its Interpretant, representing a layering of Sign, Object and Interpretant in the work of semiosis. 
In subsequent uses (beyond the second use), proper names become symbolic: "The habitual acquaintance with it [the proper name] having been acquired, it becomes a Symbol whose Interpretant represents it as an Icon of an Index of the individual named" (1905: MS 280: 27). In later uses, proper names begin acquiring specific perceptual and functional meaning associations with the name via their Interpretants; herewith they qualify as singulars, according to Peirce's (1868) elaborations on the issue in MS 931: 24. Use of proper names as singulars entails expectations, on the part of the interpreter, regarding how the referent is likely to behave or appear. These uses qualify as singulars, since the Interpretants associated with their Sign and Object include concept-based information - "boundaries of cognition" reflecting the semantic knowledge from which expectations proceed. The stored semantic information associated with the particular proper name consists in a host of common perceptual and functional properties which Objects (persons encountered by the interpreter) of that proper name share. In contrast to the classic debate in semantics between description and direct reference Peirce supplies us with a triadic system which illustrates progression from proper name association with objects (direct reference) to form related similarities between object and its Interpretant (mental image), finally to uses in which the form of the object and the Interpretant is immaterial, as in a symbolic conglomerate of adhering characteristics residing in the Sign. Interpretant's greater objectivity in subsequent uses of proper names is derived from its status as a Third of a Third - an Interpretant of a symbol. In short, the Interpretant of the proper name as symbol acquires singular status in view of increased attribution of non-physical qualities to proper name use (sign vehicle).

Peirce's two means of individuating enlighten us as to fundamental distinctions between: pronouns, proper names, and other nouns of the count and generic complexion. The nature of pronouns, on one end, as being vague terms, possessing virtually empty semantic content, places them at the pinnacle to qualify as individuals. Their heavy pragmatic dependence (not semantic) as spatial markers to orient in the context of use is an additional factor militating in favor of their status as individuals. Proper names represent a distinct case - they, like pronouns, can serve a purely individual function in their introductory uses; but afterward their acquired iconic and symbolic sign status with Interpretants guiding such use, warrant assignment as singulars. Other nouns fall at the reverse extreme - as singulars on each occasion of use. Count and mass nouns (including generics) always take their place as singulars, consequent to accompanying definitional information from their lexicon (which is incorporated into their respective Interpretants). Pronouns and proper names (when used for the first time) then, as indexical names, operate as individuals and serve a more critical individuating function than do the other types of names, in view of their brute force association of designative sign with Object. This means to individuate relies exclusively on Index (visual directionals) to fit sign to Object, and not on non-haecceity-based semantic information of kind which the Interpretant can supply.

\section{Objects in their creative function}

Within the triad, it is the Object which is foundational to sign relations, because it establishes the need for an Interpretant, particularly relevant in singular uses of pronouns, and in large part, proper name and common noun uses. An Interpretant determines the 
PJOS 5(2), 2013

kind of Object because the Object alone cannot indicate whether it is individuated as a singular (a member of a class) or as an individual. Moreover, it is the Object that predicts the kind of Sign relations (Index, Icon, or Symbol). Additionally, it is the Object which establishes the need for a concurrent Sign - when a second Sign is warranted to clarify the intended referent. In short, within the Object lies the impetus to call up stored conceptual representations (Interpretants) in the form of semantic memories to enhance meaning construal. Such power resides within the Object when the sign's sufficiency is non-analogic, such that the Sign is neither Icon nor Symbol. In cases of spatial contiguity with the Object, in which Indexes are deployed, the uniqueness of the Object has particular force to elicit attentional Signs.

Objects of pronouns possess just such power - brute attentional force to elicit indexical signs when the signs are primarily indexical. These Objects particularly stand out - they are not types, but tokens, injecting their uniqueness apart from all else. As such, their signs are most often individuals, unless they impel association with particularized perceptual or functional features of other potential Objects. “...tokens always become unique through individuation... If two tokens were identical they would be one. In the natural world no two material objects of any kind are identical" (Salthe, 1993: 141).

Objects of pronouns are regularly pieces of space, places differentiated from other places. Objects of that or there are equivocal to a place or an entity within a place out there somewhere (including but not limited to near space), not tethered to feature comparisons. Because demonstratives and first uses of proper names are indexical legisigns, and are without means to define the Object, their Objects must invoke another, visual Index (gaze, pointing) to indicate them, or must have within themselves a salience of such proportion that the sign becomes rather incidental. In this capacity, the Object of these legisigns is, as Peirce terms it, a "brute [force] reaction" Second (1898: MS 339: 295), firing another concomitant physical sign or intensifying its properties to the mind of the observers. These Objects essentially trigger the use of individuals over singulars (by virtue of their uniqueness), and reduce the effect of the Interpretant to a catch-all slot for potential meaning. So, if the Interpretant is present at all, it is characterized as an empty slot, awaiting the possibility of being filled with analogic features in the inferencing process. Here, the Interpretant exists as a potentiality or possibility.

These concurrent indexical signs have a distinctively attentional and visual character, e.g., eye gaze or pointing or some other directional gesture. In this way, Objects of individuals often call up more than one indexical sign concurrently to achieve referential success, particularly to differentiate them from a host of other potential referents. Since these concurrent signs make use of corporeal Indexes as a vehicle for object individuation, often in the form of directional looking and/or pointing, they have a particularly potent influence on early concept formation, consequent to the prominence of lived (participatory) experience as a foundational forum.

Accordingly, objects of individuals, as opposed to objects of singulars, do not access filled Interpretants. When demonstratives are employed as individuals, Interpretants appear to be immaterial in the referential act. In fact, little need arises for access to prior representations in the process of enhancing interpretation of compulsive notice of Objects; and Interpretants serve little or no fundamental purpose. In 1901, 
Peirce indicates that: "an Index ... would at once lose the character which makes it a sign if its Object were removed, but would not lose such character if there were no Interpretant," (CP2.304). Objects of individuals are indispensable; and they do not ordinarily give rise to covert representations in the referential act; rather, it is the cooccurrence with their Sign and their appeal to uniqueness which secures the semiotic connection.

These Objects may be existents, or may materialize as constructions in the imagination. Whatever is salient: tangible/intangible inanimate objects, animates, individually invented smurfs, sneezes, shadows, and the like, can constitute an Object of an individual. The diversity of potential Objects, coupled with the sudden, compulsive imposition of these Objects upon the consciousness of two parties accounts for the dispensability of Interpretants in related semiotic acts. Because the properties of these Objects are not similar, joint attentional schemes are necessary to elicit notice from one or both parties in the conversational exchange.

Kockelman (2011: 167) affirms that semiotically Objects are not limited to tangible referents. He asserts that Objects are not necessarily objective entities, but intersubjective processes, focusing on complex propositions and intangibles.

\footnotetext{
An object, then, is whatever a signer and interpreter can correspondingly stand in relation to - it need not be continuously present to the senses, taking up volume in space, detachable from context, or 'objective' in any other sense of the word (Kockelman, 2011: 167).
}

This amplifies the array of potential Objects which demonstratives can indicate. The Object is given a diminished role by Kockelman (2011: 174). He claims that relations pertaining to Objects are processes, which signers are responsible to invent and declare, and fails to recognize the force of the Object to compel the type of sign with which it becomes associated, or to elicit the signer's notice. According to Kockelman, signers are, without question, the source for sign inception - signers "bring into being the sign."

In point of fact, once the sign has been imbued with existence, it is the Object (given its means to ground the triad) which creates which Sign type is most appropriate to illustrate features of the Object: individuals or singulars. This potency does not reside within the sign or the intentionality of the signer here. In fact, the signer's focus can (without much effort) be interrupted forcibly by insinuations of Object(s) upon the signer's consciousness. The quintessential example of Object privilege is the influence of the Object to define uses of the demonstrative pronoun (the Sign). Because the Sign here does not specify characteristics of its referent Objects, given its status as an individual rather than a singular, the responsibility to specify identifying characteristics shifts to the Object. In short, the increased influence of the Object upon individual signs illustrates contexts in which the sign/signer is consigned to a less dominant role in the establishment of meaning.

\section{Preeminence of pronoun selection}

Objects of Peirce's individual type elicit signs which can best showcase their discreteness, not their commonalities with other entities. As such, they select "pure" Indexes to highlight their location and identity, and are not likely to select Symbols. Accordingly, although individuals (pronouns, first instances of proper names) do not constitute names in the strict, classic sense of naming, in that their lack of obvious 
PJOS 5(2), 2013

physical and functional attributes militates against comparing them with an exemplar and ultimately determining into which class of objects they best fit. Pronouns and first instances of the proper name do qualify as names, and names of a rather perfect vintage for Peirce. If nouns are "imperfect" specimens of individuating, because they "do what the pronoun does at once" (1893: CP2.287 fn1), their naming function is actually superior, not inferior, given their natural way of naming Objects with attentional signs.

Although individuals do not name in the classic way of naming, or by means of a best exemplar approach, they clearly constitute signs which force attention on their referents - a primary function of names. Nouns, on the other hand, are subject to the best exemplar approach of Rosch et al. (1976). It is premised on the claim that concepts consist in typical and less typical exemplars, and that the most common exemplar represents the best exemplar of that category or concept. Less typical exemplars are hierarchically organized within the category, such that they are found at its periphery. With respect to Objects which impel demonstrative pronoun use, and perhaps with all Objects of individuals, best exemplars do not even enter into the equation - one use of that does not represent a more typical exemplar of "thatness," since compulsive attention to salient Objects is at its core. Hence, in light of the directional, attentional function of individuals, the model of Rosch et al. (1976) breaks down. Objects of individuals are a special case, since essentially no nucleus or periphery can be established with respect to the typicality of Object-Sign associations.

In fact, individuals (especially demonstratives) strip their signs of the means to subsist as best exemplars of a class, when they are used instead of singulars. The choice of that (compelled by non-concept-driven naming of Objects) in place of nouns equalizes and perhaps reduces all objects to salient entities - wiped clean of any semantic affiliation. This process of "wiping clean" the noun by substituting a pronoun actually appears to represent the starting point or zero point of naming, namely, transforming speaker's focus on an Object to a joint attentional venture; and without this attentional paradigm, naming is likely to be stripped of its primary purpose - to direct or force attention on an Object. In view of the Object's (particularly applicable to demonstrative pronouns) need for joint attentional signs, their preeminence in the naming process is unquestionable.

Peirce supports this line of reasoning - that pronouns are preeminent in the naming process - when he asserts that nouns derive from pronouns, not the reverse (as many have assumed).

\footnotetext{
...there is no reason saying that ' $I$ ' 'thou' 'that' 'this' stand in place of nouns; they indicate things in the directest possible way. It is impossible to express what an assertion refers to except by means of an Index. A pronoun is an Index. A noun, on the other hand, does not indicate the object it denotes; and when a noun is used to show what one is talking about, the experience of the hearer is relied upon to make up for the incapacity of the noun for doing what the pronoun does at once. Thus, a noun is an imperfect substitute for a pronoun (1893: CP $2.287 \mathrm{fn} 1)$
}

Peirce is adamant that the pronoun is primary, and that it is the pronoun which has greater means to individuate. As such, nouns (when they replace pronouns) are an "imperfect substitute." Because of exclusive focus on their Object's uniqueness, and because of the legisign's vague, all-encompassing nature, pronouns can point in a 
universal way, such that they are relatively free from semantic wrapping. This compulsive dependence on the pronoun liberates the signer from casting about for the most suitable singular sign - ordinarily a noun which classifies the Object. Instead, signers can plug in an individual sign (the demonstrative pronoun), and need not access stored semantic knowledge necessary for Object classification. Employing a demonstrative pronoun in lieu of a noun can be quite automatic, requiring far less on-line deliberation. Reliance on that, for example, allows the signer to forego the process of settling upon a fitting conventional singular sign which may depend upon increased conscious control over stored memories, not necessarily at the signer's disposal. Although nouns individuate Objects, the individuation is not as effectual to celebrate the Object's differentness, when compared with the riveting effect of individual signs.

In fact, when the Object constitutes a supremely insinuating device on the consciousness, Index must appeal to and frame just such manifold differentness. Accordingly, pronouns (as Indexes and individuals) take precedence over nouns, because of their greater universal ability to refer to Objects apart from their inclusion in a class. Finally, unlike singulars, Objects of individuals, ordinarily individuated in event structures in space and time, require as pure an Index as possible, often supplied by demonstrative pronouns.

The pronoun, which may be defined as a part of speech intended to fulfill the function of an Index, is never intelligible taken by itself apart from the circumstances of its utterance; and the noun, which may be defined as a part of speech put in place of the pronoun, is always liable to be equivocal," (1903: CP 5.153, from Harvard Lecture 6).

The noun is "equivocal" when it individuates via the spatial context - an unnatural function for nouns. If one wishes to individuate via an individual sign, not a singular, for purposes of singling out a noun, e.g., "look at the thing [which I am looking at]" is less effectual than the use of the demonstrative pronoun that. "The thing" intimates that the signer is experiencing difficulties accessing a fitting singular term (a more specific noun, e.g., the plant; consequently, its use to substitute for the demonstrative pronoun detracts from simply drawing the attention to a unique specimen of focus - that. What the noun ordinarily establishes is a name/type of thing. The demonstrative pronoun, on the other hand, wills the signing partners not to categorize, but to appreciate the object's distinctive attributes. In their use as Indexes, pronouns are responsible for "indexical thrusts" to establish vantage points and to restrict referent places. In sum, unlike noun relations, Objects of individuals refer to entities and places out there which elicit as pure an Index as can exist.

While all three (pronouns, proper names, and nouns) are legisigns, only pronouns (especially demonstratives) reliably refer in a global manner, such that they compel more than a single indexical sign. In contrast, proper names and some third person pronouns, particularly in their initial use, carry some particular attribute or class feature(s), such as gender in the case of Sally. Conversely, the global character of pronouns allows the same sign to attend to infinite Objects and Object types, mandating the use of Index. Such is a more "perfect" sign, given the economy of its application - the signer need not search for a specific fitting name which contains specifiable properties.

Nonetheless, what may advantage pronouns in some uses may (in other uses) serve to discourage their selection. Their vagueness and/or globality can result in greater ambiguity and greater dependence on a concomitant Index. The need for a second Index 
PJOS 5(2), 2013

to draw a visual line (if you will) from the signer to the Object can be a less expedient means to represent an Object, e.g., pointing along with the demonstrative. This disadvantage is particularly poignant if the Object is not co-present with the Index, as is the case with absent Objects. In this case, it becomes more expedient to select a noun to specify the absent Object. Consequently, if sufficient linguistic means is at the signer's disposal - use of singulars, their selection may absolve him or her of the need to invent and implement a second Index to show the Object. Implementing a single singular (proper name, common noun) rather than two Indexes toward the identical end requires far less effort in Secondness, provided that sufficient linguistic sophistication is in place.

Peirce acknowledges distinct disadvantages of pronouns, especially demonstratives. In 1893-95: MS 409: 100-101, Peirce states that the demonstrative is as bad as it can be: "...They [demonstratives] are as bad as they can be. They demonstrate nothing. They do not even exhibit anything; they only show in the sense of directing the hearer where to search for the thing meant." Why "bad?" If visual attentional vectors lack sufficient precision to bind the association between Index and Object, little is communicated. If attentional strategies in the form of visual, often uni-directional Indexes do not, or cannot show the Object, it may be that the Immediate Object is overly vague to hasten association of the Dynamical Object to the Index. Peirce lays great store in the fact that the two types of Objects give rise to distinct functions:

\footnotetext{
...yet in a general way I have made it clear what I mean by the object and what by the interpretant of a sign. The object is the sign's determinant; the interpretant is the determinand of the sign and through the sign of the object likewise.

But now I must call attention to the circumstance that every sign has two objects. It has that object which it represents itself to have in immediate Object, which has no other being than that of being represented to be, a mere Representative Being, or as the pre-Kantian logicians used to say a merely Objective Being; and on the other hand there is the Real Object which has really determined the sign which I usually call the Dynamical Object and which alone strictly conforms to the definition of the Object. The Object of a Sign is its progenitor, its father. The Dynamical Object is the Natural Father, the Objective Object is the putative father (n.d., n.p.: MS 499: 86 - MS 499s: 2).
}

Peirce articulates that both the Dynamical and the Immediate Object constitute "progenitors," but progenitors of different types. He explicitly distinguishes between the "natural" fit of the Dynamical Object and the "putative" role of the Immediate Object. The Dynamical Object refers to the insinuation of the Object as an individual Object with the force that it can muster over the signer and over sign selection; consequently, Peirce decrees it to "really determine the Object." The Immediate Object, in contrast, consolidates instantiations of the Object, such that Interpretant slots begin being filled. Immediate Objects are not "natural Fathers," but "putative" ones; consequently, their relationship with members of the triad is more contrived, constructed over time with experience. Dynamical Objects, on the other hand, have a direct, primary relationship with their signs and materialize suddenly, typically requiring coexistence between the two. When pronouns serve as individuals their Immediate Object is non-existent or inaccessible, since Peirce's requirement of objectivity - inclusive of all likely instantiations - is not operational. Conversely, because the Dynamical Object (the "real Object") is the brute force experience of the Object upon the sign and the signer, its sign 
materializes in individual uses of pronouns. More importantly, absent the individual nature of the Dynamical Object to beckon an attentional Index exemplifying spatial trajectories of source, path and destination, early sign-Object relations would be truncated at best. Thus, this individual nature further affirms Peirce's fitting characterization of an Object of individuals as the "natural Father."

Individuation can be effectuated as much by singulars as by individuals; and hidden, absent, and covert objects can be successfully identified, despite the lack of spatial contiguity between Sign and Object. What pronouns (particularly demonstratives) do effectuate well is to "direct the hearer to where to search for the thing meant" (18931895: MS 409). The pronoun as an indexical legisign is privileged; it provides primary spatial information to enhance notice of Objects, which nouns and proper names do not do naturally. This is in keeping with Langacker's (2009: 149) claim that demonstrative pronouns are one of a few elements which have the unique function to alone ground the clause, by virtue of their attentional character. Accordingly, Langacker (2009: 151) asserts that grounding is not merely a syntactic affair; rather, it likewise establishes "epistemic control" among interlocutors, by attempting to rivet the attention of the other partner on the same physical/mental phenomena as the speaker. Although Langacker appears to attribute this attentional potency to the spatial boundedness of the nominal, what actually underlies the spatial function is left unaddressed. If examined in light of the semiotic distinction of nouns, but especially between nouns and pronouns (particularly demonstratives) one can uncover the increased indexical nature of the pronoun over the noun. This difference has its roots in the shifting, deictic character of pronouns, quintessentially demonstratives (West, 2013: 3-6). Demonstratives, with their objects, are more likely than are nouns to ground the communicative act. Their potency to ground in the communicative forum emanates from their primary role to identify uniquely, without reference to other objects in memory or in the context (unlike mass/count nouns). Hence, pronouns (as Indexes) serve as an invaluable source for Object notice and for successful sign-referent association. Moreover, Objects of pronouns more directly impinge upon the consciousness, since (unlike most uses of proper names and nouns) they need not rely upon Immediate Objects and/or Logical Interpretants for interpretation; rather, Dynamical Objects define the referent and select the Sign.

Although nouns likewise individuate, they do not brutely announce the uniqueness of their Objects. The attentional function of nouns is far less effectual. They do, however, provide semantic information via the Immediate Object, not present in pronouns or in initial uses of proper names. Nouns are used to show what is being talked about, not where or when. As such, nouns (unlike pronouns) require far more controlled and more conscious access to semantic knowledge. Their use also entails knowledge of and negotiation between the mental representations distinct to the speech partners. The experience of the hearer that is relied upon is not merely a single exposure to the Dynamical Object, as is the case for most pronouns, but involves an integration of what the speaker knows about kinds of Objects. 
PJOS 5(2), 2013

\section{Conclusion}

Both individual (largely via pronouns) and singular (largely by way of nouns) means of individuating are indispensable to semiosis, although pronouns have a privileged place, given their indexical function. Pronouns, particularly demonstratives, are the only sign of the three which can impart a purely indexical function (as individuals), but which (later in ontogeny) can likewise function as singulars. The attention which pronouns commandeer in beckoning notice of peculiarities in the haecceity of lived experience, qualifies them as quintessential individuating devices. As individuals, pronouns hasten notice of Objects as discrete units for later analysis/classification, which preempts later synthesis of objects and action trajectories into episodes or event structures. Pronouns then can best measure semiosis, since they transition from solely attentional devices in embodied experience to proximal or distal markers, incorporating concepts into the mix. Hence, Peirce's distinction between individuals and singulars effectively provides the theoretical mechanism to chart the semiosis of linguistic indexical signs. While individual uses of demonstrative pronouns celebrate their Objects' uniqueness, singular uses celebrate that which nouns and proper names express, sameness with like objects, deemphasizing the Dynamical Object, while profiling the Immediate Object. The upshot is that Interpretants categorize the Object as an alike experience (with respect to prior ones) for nouns/proper names, whereas for pronouns, Objects largely define the experience as distinctive/discrete.

\section{References}

Atkin, A. (2005). Peirce on the index and indexical reference. Transactions of the Charles S. Peirce Society 16(1), 161-188.

DiLeo, J. (1991). Peirce's haecceitism. Transactions of the Charles S. Peirce Society 27(1), 79-109.

Hilpinen, R. (2012). Types and tokens: On the identity and meaning of names and other words. Transactions of the Charles S. Peirce Society 48(3), 259-284.

Kockelman, P. (2011). Semiotics: Interpretants, inference, and intersubjectivity. In R. Wodak, B. Johnstone, \& P. Kerswill (Eds.), The SAGE handbook of sociolinguistics, (165-179). London: SAGE Publications

Langacker, R.W. (2009). Investigations in Cognitive Grammar. Berlin: Mouton de Gruyter.

Peirce, C.S. (i. 1867-1913). Collected Papers of Charles Sanders Peirce. Vols. 1-6 edited by C. Hartshorne \& P. Weiss. Cambridge, Massachusetts: Harvard University Press, 1931-1966. Vols. 7-8 edited by A. Burks. Cambridge, Massachusetts: Harvard University Press, 1958. [Cited as CP X.XXX]

Peirce, C.S. (i. 1867-1913). The Essential Peirce: Selected Philosophical Writings. Vol. 1, N. Houser \& C. Kloesel (Eds.); Vol. 2, Peirce Edition Project, (eds.). Bloomington: University of Indiana Press, 1992-1998. [Cited as EP X: XXX]

Peirce, C.S. (i. 1867-1913). Unpublished manuscripts are dated according to the Annotated Catalogue of the Papers of Charles S. Peirce, ed. R. Robin (Amherst: 
University of Massachusetts Press, 1967), and confirmed by the Peirce Edition Project (Indiana University-Purdue University at Indianapolis). [Cited as MS XX: $\mathrm{XXX]}$

Peirce, C.S. (i. 1884-1886). Writings of Charles S. Peirce: A Chronological Edition. Vol. 5, Peirce Edition Project (eds.). Bloomington: University of Indiana Press, 1993. [Cited as WX: XXX]

Riley, G. (1974). Peirce's theory of individuals. Transactions of the Charles S. Peirce Society 10(3), 135-165.

Rosch, E., Mervis, C., Gray, W., Johnson, D., \& Boyes-Braem, P. (1976). Basic objects in natural categories. Cognitive Psychology 8: 382-432.

Salthe, S.N. (1993). Development and Evolution: Complexity and Change in Biology. Cambridge, MA: MIT Press.

Scotus, J.D. (i. 1290-1295). Early Oxford Lecture on Individuation. Trans. Fr. A. Wolter. St. Bonaventure: Franciscan Institute Press, 2005.

West, D. (2011). Deixis as a symbolic phenomenon. Linguistik Online 50(6), 89-100.

West, D. (2013). Deictic Imaginings: Semiosis at Work and at Play. Heidelberg: Springer Verlag.

Whitney, W.D. (1889). The Century Dictionary and Cyclopedia. New York: The Century Press. [Cited as CD XXX] 